\title{
A Sexualidade, a saúde reprodutiva e a violência contra a mulher negra: aspectos de interesse para assistência de enfermagem
}

\author{
SEXUALITY, REPRODUCTIVE HEALTHAND VIOLENCE AGAINST THE AFRICAN \\ BRAZILIAN WOMEN: ASPECTS OF INTEREST FOR NURSING CARE
}

SEXUALIDADE, SALUD REPRODUTIVA Y VIOLENCIA CONTRA LA MUJER NEGRA: REVISIÓN DA LITERATURA DE INTERES PARA EL CUIDADO DE ENFERMERÍA

\section{Isabel Cristina Fonseca da Cruz ${ }^{1}$}

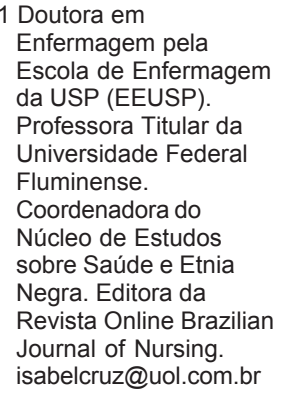

\begin{abstract}
RESUMO
Com base no referencial da teoria racial crítica, foi feita uma revisão da literatura com o objetivo de buscar informações que fundamentem uma ação profissional afirmativa contra o racismo e o sexismo, baseada em evidências científicas e culturalmente competente. Evidenciou-se que a sexualidade, a saúde reprodutiva e a violência contra a mulher negra são temas com literatura escassa, sugerindo que o racismo e o sexismo estão operantes por meio da omissão ou negligência do Estado pese a mobilização das mulheres negras. Concluiu-se que a discriminação institucional precisa ser explicitada e combatida por meio de várias ações afirmativas em relação à mulher negra que devem ser implementadas ou fortalecidas para a promoção da eqüidade em saúde.
\end{abstract}

\section{DESCRITORES}

Mulheres.

Saúde da mulher.

Violência.

Sexualidade.

Discriminação racial.

\section{ABSTRACT}

Based on the referential of the critical racial theory, a review of the literature was made with the objective of searching for information that leads to an affirmative professional action against racism and sexism, based on scientific evidences and culturally competent. It was evidenced that the sexuality, reproductive health and violence against African Brazilian women are themes with scarce literature, suggesting the omission and neglicence of State to weigh on African Brazilian women's mobilization. The study concluded that institutional discrimination in health needs to be neutralized by affirmative actions regarding to African Brazilian women that must be implemented or strenghten to promote equity in health. that racism and sexism occur by

\section{RESUMEN}

Con base en el referencial de la teoría racial crítica, se realizó una revisión de la literatura con el objetivo de buscar informaciones que fundamenten una acción profesional afirmativa contra el racismo y el sexismo, basada en evidencias científicas y culturalmente competentes. Se evidenció que la sexualidad, la salud reproductiva y la violencia contra la mujer negra son temas con literatura escasa, sugiriendo que el racismo y el sexismo están operantes por medio de la omisión o negligencia del Estado, pese a la mobilización de las mujeres negras. Se concluyó que la discriminación institucional precisa ser explicitada y combatida por medio de varias acciones afirmativas en relación a la mujer negra y deben ser implementadas o fortalecidas para la promoción de la equidad en salud.

\section{DESCRIPTORES}

\section{DESCRIPTORS}

Women.

Women's health.

Violence.

Sexuality.

Racial discrimination.
Mujeres.

Salud de la mujer.

Violencia.

Sexualidad.

Discriminación racial. 


\section{INTRODUÇÃO}

Este estudo teve como motivação inicial o Fórum Internacional Sobre Sexualidade, Saúde Reprodutiva e Violência Contra a Mulher na Amazônia Ocidental, promovido pela Universidade do Acre, em setembro de 2003, por ter aberto uma oportunidade de discutir com os profissionais e gestores da saúde sobre a condição das mulheres negras no Brasil e no mundo. Eventos desta natureza têm relevância científica porque permitem trazer à tona assuntos que a sociedade insiste em manter fora da sala de visita: racismo e sexismo. Em Fóruns como este, podemos delinear um quadro atualizado sobre as condições de saúde/doença, bem-estar e mal-estar das mulheres negras, a partir de suas próprias representações e propor políticas afirmativas que ajudem na promoção da saúde das clientes e na superação dos problemas. Têm ainda relevância social por propiciarem a explicitação das condições de desigualdade em que vivem as mulheres negras, quando comparadas aos demais estratos sociais, devido à sua cor ou grupo étnico e por darem subsídios para os gestores e profissionais de saúde formular políticas que favoreçam o acesso ao cuidado e à qualidade do mesmo.

\section{DESCRIÇÃO DO PROBLEMA, DO REFERENCIAL CONCEITUAL E DO OBJETIVO DO ESTUDO}

O problema de pesquisa que trataremos neste estudo é a escassez de informação sobre a demanda ou necessidade que a mulher negra possui em relação às instituições e aos profissionais de saúde, em especial às enfermeiras, quanto à sua sexualidade, sua saúde reprodutiva e às situações de violência. Também se dirá do quanto essa demanda justifica o estabelecimento de políticas afirmativas de promoção da saúde a serem implementadas, visando à eqüidade.

Assim, para melhor compreensão do problema racial e de gênero no Brasil e para análise do conhecimento produzido sobre a condição das mulheres, buscamos utilizar como referencial a teoria racial crítica $^{(1)}$. Esta teoria estrutura-se em torno de dois eixos fundamentais: a equidade e a democracia. Assim, constructos como meritocracia, neutralidade, objetividade, entre outros, são todos questionáveis.
Uma vez que o racismo é um viés, tanto das epistemologias tradicionais quanto contemporâneas, que orienta a condução de pesquisas e interpretação de resultados que refletem e reforçam a história social, racial e de gênero do grupo hegemônico, surgiu a necessidade de construir uma epistemologia que estivesse associada ao desenvolvimento do pensamento afrodescendente formado ao longo de cinco séculos de exclusão nas Américas.

Neste sentido, como parte do pensamento afrodescendente, observou-se que o sistema social de direitos civis, liberal e conservador, estava estruturado de modo a valorizar a propriedade em vez da justiça e que os avanços sociais só seriam promovidos pelo grupo hegemônico caso também promovessem seus próprios interesses. Por fim, o grupo hegemônico só aceita o custo das soluções para os problemas raciais e de gênero caso estas soluções não ameacem seu status quo.

Por meio da teoria racial crítica, fenômenos e eventos tidos como reais ou naturais, cristalizados na estrutura social (como o racismo e o sexismo), foram modelados por uma série de fatores sociais e precisam ter seus significados mais profundos revelados para que se possa compreender e abordar os problemas sociais contemporâneos.

A teoria racial crítica reconhece que a pessoa discriminada racialmente tem seu discurso referenciado pelo racismo, porém, de modo a estudar sua perspectiva, este discurso precisa ser compreendido. Portanto, as histórias das pessoas vitimizadas por iniqüidades raciais e de gênero sobre suas experiências constituem uma evidência empírica sobre a realidade. Por meio destas evidências, o pesquisador orientado pela teoria racial crítica busca revelar as forças sistêmicas enraizadas na sociedade que atuam na opressão racial e de gênero.

Com base neste referencial, procuramos observar o quanto a condição da mulher negra se aproxima ou se distancia da justiça e igualdade de chances em conquistar as oportunidades apresentadas pela sociedade (princípio da eqüidade), assim como quanto a sua condição feminina propicia a sua participação plena nas instituições de controle social (princípio da democracia).
A sexualidade, a saúde reprodutiva e a violência contra a mulher negra: aspectos de interesse para assistência de enfermagem 
Além disso, quando se estuda a mulher negra brasileira, julgamos importante frisar a existência do fator extrínseco histórico-sociológico caracterizado por quatro séculos de escravidão e um século de exclusão, sob o arcabouço do patriarcado $^{(2)}$. Assim, por meio da análise crítica da história brasileira, incluindo a contemporânea, observamos que as condições de escravização, colonização, patriarcado e exclusão moldaram uma realidade e cristalizaram estruturas que são inadequadamente entendidas como legítimas e impuseram às mulheres negras, no que tange a sua saúde, fatores de risco extra-biológicos os quais apontaremos mais adiante neste estudo.

Nossa experiência profissional e de vida, nos autoriza partir do pressuposto que também na área da saúde existe racismo institucional ${ }^{(3)}$ e este pode ser evidenciado/ detectado em processos, atitudes ou comportamentos que denotam discriminação derivada de estereótipos, preconceito inconsciente, ignorância ou falta de atenção e que colocam pessoas e grupos em situações de desvantagem. Portanto, a persistência de uma estrutura de discriminação pode ser decorrente, entre outras razões, do desconhecimento existente a respeito da demanda da mulher negra sobre suas condições de vida e saúde.

Diante do exposto, traçamos como objetivo a realização de um estudo bibliográfico sobre a literatura profissional que propicie relacionar os problemas de saúde/doença, bem-estar/mal-estar vivenciados pelas mulheres negras, particularmente aqueles relacionados à sexualidade, à saúde reprodutiva e à violência, assim como apontar intervenções afirmativas, que visam a equidade, passíveis de ser implementadas pela própria cliente, pelos profissionais/instituições de saúde, pela sociedade civil organizada e pelos gestores do Sistema Único de Saúde (SUS).

Enquanto o SUS não viabiliza a coleta de dados empíricos e a sua análise desagregada por raça/cor e gênero, consideramos relevante a investigação do discurso acadêmico sobre o problema, tendo em vista que é ele quem molda a formação e a atuação dos profissionais e gestores de saúde.

O estudo bibliográfico foi realizado na base de dados SciELO, utilizando como palavras-chave: mulher, mulher negra, violência, sexualidade, entre outras; e na Biblioteca Vir- tual Mulher (BVM), no período 1990-2003. Foram encontrados quatro artigos relacionando mulher e violência; cinco artigos: mulher e negra; e quatro sobre mulher e sexualidade. Dos encontrados, selecionamos aqueles relacionados ao tema proposto.

\section{DESENVOLVIMENTO}

Os resultados da pesquisa bibliográfica com base no recorte temporal, no nosso entendimento, mostraram que são escassos os números de textos sobre saúde da mulher negra, assim como o número também restrito de publicações específicas sobre violência contra as mulheres ou violência doméstica, ainda que pelo senso comum saibamos que a dimensão do fenômeno não é pequena. Para nós, do Núcleo de Estudos sobre Saúde e Etnia Negra-NESEN( ${ }^{(4)}$, esta escassez revela o contínuo descompasso entre os problemas que a academia considera "pesquisáveis" e os reais problemas vivenciados pela clientela.

O não reconhecimento das diferenças e $o$ desrespeito a elas também constituem padrões de violência e discriminação ${ }^{(5)}$. Os resultados deste continuado desconhecimento, isto é, deste racismo epistemológico ${ }^{(1)}$, sobre aspectos relativos às mulheres negras, em particular, podem ser notados pelos baixos indicadores sociais e de desenvolvimento, assim como pela demora em se estabelecer políticas públicas afirmativas na área da saúde e da educação que promovam o bemestar social e a qualidade de vida deste segmento da população.

\section{Análise e interpretação}

Os resultados do perfil de saúde/doença da mulher negra de uma região rural da Grande São Paulo ${ }^{(6)}$ revelaram que a maioria era casada, católica, possuía o $1^{\circ}$ grau incompleto, encontrava-se entre 26 e 35 anos, e trabalhava no lar. Quanto à sexualidade, 21,7\% negaram ter satisfação sexual; a pílula era o método contraceptivo de maior freqüência, seguido pela laqueadura (17,9\%). A pressão alta era o fator de risco familiar mais freqüente $(50,3 \%)$ e, enquanto patologia, estava presente em $24,8 \%$ da clientela (PAD $>=90 \mathrm{mmHg}$ ). As autoras concluíram sobre a necessidade de estender este estudo à população urbana e aprofundar a investigação sobre os indicadores negativos e seu impacto no processo saúde/doença. 
Com base nos dados fornecidos pela RIPSA (Rede Interagencial de Informações para a Saúde) sobre a taxa de mortalidade no Estado de São Paulo, no ano de 1999, verificou que a expectativa de vida ao nascer é, em média, 70 anos para homens e mulheres ${ }^{(7)}$. Porém, há significativa diferença entre os gêneros e os grupos étnicos. A mulher negra tem uma expectativa de vida de 66 anos, contrariando a tese de que as mulheres vivem mais, pois o homem branco tem uma expectativa de vida de 69 anos. A maior expectativa de vida é a da mulher branca: 71 anos enquanto o homem negro é a menor: 62 anos. Ainda que mulheres e homens negros se beneficiem de algum modo dos avanços da ciência e da economia, a manutenção da discriminação, da pobreza e da violência contra os grupos não hegemônicos explica os valores inferiores quanto ao tempo de vida.

Um exemplo da política discriminadora institucional de gênero e raça é não só o índice de mortalidade materna como também a diferença escandalosa e criminosa desta taxa em relação às mulheres negras e brancas. A taxa de mortalidade materna é de 51,7/100.000 nascidos vivos ${ }^{(5)}$, mas nas mulheres brancas é de 37,73 . Se esses números já são inadmissíveis, era de se esperar um clamor de indignação quanto à taxa de mortalidade materna nas mulheres pretas ser de 212,80! Quase seis vezes mais do que a taxa de mulheres brancas! Cabe observar ainda que a taxa mortalidade de 65,51 nas mulheres não-brancas também é elevada. Porém, uma importante implicação sobre estes dados para as(os) enfermeiras(os) é que estas mortes são em sua maioria por causas evitáveis (síndromes hipertensivas, hemorragias, infecções puerperais e complicações do aborto) e, infelizmente, indicam o grau de (má) qualidade da assistência de saúde prestada durante o ciclo grávido-puerperal. A brutal diferença das taxas de mortalidade materna entre os grupos étnicos aponta para a possibilidade de os profissionais de saúde poderem vir a ser denunciados pelo crime ético negligência em razão de preconceitos sobre a característica racial da clientela.

Além das diferenças na expectativa de vida e na taxa de mortalidade materna, podemos observar o impacto que o racismo, o sexismo e a discriminação podem ter sobre a saúde mental por meio de dois diagnósticos de enfermagem importantes: distúrbio da auto- estima e distúrbio do auto conceito. Verificou-se ${ }^{(8)}$ uma acentuada insatisfação das mulheres negras com a aparência, pois $46,5 \%$ delas mudariam algo no corpo (cabelo e o nariz). Com base na teoria racial crítica, consideramos que os dados encontrados revelam uma mulher discriminada racialmente, cujo discurso é referenciado pelo racismo e, por conseguinte, suas experiências podem ser consideradas como uma evidência empírica sobre a realidade brasileira que se auto-define como uma democracia racial.

Neste sentido, o distúrbio da auto-estima e o distúrbio do auto conceito podem ser conseqüências do sofrimento psíquico. Igualmente, este sofrimento psíquico decorrente da opressão pode estar materializado na taxa de mortalidade por transtornos mentais, cuja diferença numérica nos óbitos entre os grupos étnicos pode ser resultante de um tratamento racializado. Isto porque, nas mulheres pretas, a taxa de mortalidade por transtornos mentais é de 3,29 ; enquanto que nas mulheres brancas é de 1,92 .

A título de ilustração, no que se refere à taxa de mortalidade por transtornos mentais, parece-nos também que a mulher negra apresenta um resultado (outcome) de enfermagem que é o enfrentamento do estresse ${ }^{(9)}$ quando comparada ao homem negro. Além do racismo, há para o homem negro o peso do patriarcado, ou melhor, o peso do fracasso em cumprir o estereótipo de patriarca e provedor, pois a taxa de mortalidade por problemas mentais é neste grupo é de 19,58 , ao passo que para os homens brancos é de 6,38.

No que tange à sexualidade da mulher negra, a autora observou que a compreensão sobre saúde sexual da mulher negra (sujeito) não deve levar em conta o corpo (sensualidade), as relações de gênero (sexualidade) e as relações políticas (emancipação) ${ }^{(10)}$. A partir deste entendimento de que a sexualidade compreende as relações que extrapolam os limites da alcova, verificamos que além da insatisfação das mulheres negras com a própria aparência, há neste grupo um maior número de casamentos formais e endogâmicos $(59,2 \%)$ ou vida marital $(18,8 \%)^{(8)}$.

No que se refere à família, gostaríamos de ressaltar para as(os) enfermeiras(os) que, além da menor expectativa de vida, as mulheres negras ainda têm mais uma sobrecarga ideológica para superação: o sexismo. Portanto,
A sexualidade, a saúde reprodutiva e a violência contra a mulher negra: aspectos de interesse para assistência de enfermagem 
um dos desafios atuais na prevenção e controle do HIV/AIDS é justamente a proteção das mulheres casadas, com relação estável, e que foram submetidas ou optaram pela laqueadura de trompas como método de contracepção. Neste grupo estão as mulheres negras. Das mulheres contaminadas com HIV, a forma de contágio foi o relacionamento conjugal para $98 \%$. Nas mulheres contaminadas por HIV/AIDS, $82 \%$ são negras ${ }^{(11)}$. Conseqüentemente, vemos que a taxa de mortalidade no Estado de São Paulo( ${ }^{(7)}$, por exemplo, em decorrência da AIDS, é de 11,39 em mulheres pretas e 5,56 em mulheres não-brancas (pardas, amarelas e indígenas ou não -declaradas), enquanto que nas mulheres brancas a taxa é de 4,92.

Assim, ressaltamos neste estudo que para nós, enfermeiras(os), os fenômenos apresentados pela clientela (mulher, família e comunidade) na esfera da sexualidade, em decorrência da sobreposição (ou intersecção) do sexismo e do racismo, são passiveis de diagnósticos, tratamentos e resultados de enfermagem. Para tanto, sugerimos implementar intervenções que possibilitem o empoderamento da cliente, assim como o desenvolvimento de estratégias de negociação e decisão. Porém, um complicador importante no processo de fortalecimento das relações interpessoais e da emancipação feminina é que as mulheres negras, em sua maioria $(74,7 \%)$, não têm o $2^{\circ}$ grau, situação que coloca esta parcela da população em desvantagem quanto às condições de vida e trabalho, necessárias para garantia de bem-estar e saú$\mathrm{de}^{(8)}$. Contudo, as autoras evidenciaram que as mulheres negras possuem uma compreensão, em sua maioria absoluta $(93 \%)$, sobre a necessidade de se organizarem para a superação dos problemas sociais. E isto, no nosso entender, abre uma perspectiva de mobilização deste grupo para, entre outros aspectos, aumentar sua participação no controle social do SUS.

No que se refere à saúde reprodutiva da mulher negra, analisamos anteriormente as diferenças na taxa de mortalidade materna entre os grupos étnicos e constatamos que, por vivermos em uma sociedade que tem referenciais de opressão na sua estrutura ${ }^{(5)}$, no corpo e na mente da(o) oprimida(o) é que estas ideologias se expressam. Assim, fica fácil entender a relação entre violência racial e saúde reprodutiva quando atentamos para a divulgação de uma recente pesquisa na cidade do Rio de Janeiro, feita pela Fiocruz (Fundação Oswaldo Cruz), onde se verificou que os hospitais e maternidades, públicos e particulares, tratam melhor as gestantes brancas do que as negras. Conclusão: o tipo de atendimento é diferenciado pela cor durante a gravidez e até na hora do parto ${ }^{(12)}$. Cabe ressaltar que a desigualdade aconteceu mesmo quando as entrevistadas, brancas e negras, pertenciam à mesma classe social e tinham o mesmo nível de escolaridade. Esta evidência faz cair por terra o mito compartilhado pela direita e pela esquerda de que o problema racial no Brasil é de classe e não de origem étnica. A pesquisa revelou que os profissionais de saúde não são anjos, mas humanos e, por conseguinte atuam segundo referenciais subjetivos. Conforme estes referenciais, podem violar direitos humanos fundamentais e, assim, também violar seu código de deontologia.

Infelizmente, pesquisas sobre a qualidade do cuidado prestado conforme a origem étnica do cliente ainda são escassas no Brasil e, apesar da força dos dados, não conseguiram ainda sensibilizar os gestores para o combate à discriminação nas instituições de saúde. Em atenção ao Plano de Ação da Conferência da Organização das Nações Unidas contra o Racismo, em Durban, África do Sul em 2001, a OPAS/OMS ${ }^{(13)}$ elaborou uma proposta sobre política de saúde da população negra brasileira. Contudo, até o momento o Ministério da Saúde não se mobilizou no sentido nem de adotar nem de rechaçar a proposta. Afinal, não tomar posição também é uma decisão política.

Assim, mais um desafio é posto para as(os) profissionais de saúde: compreender que a saúde reprodutiva da mulher negra é uma questão política e como tal deve ser abordada, pois os sistemas de opressão fazem no corpo da mulher negra uma intersecção onde vários estereótipos se sobrepõem. Os resultados mais visíveis deste processo são a manutenção da ignorância, a desumanização da vida sexual e procriativa e a "culpabilização" da vítima pelos resultados negativos. Objetivamente, a(o) enfermeira (o) culturalmente sensível e comprometida (o) com a eqüidade já compreendeu que na área da saúde reprodutiva não bastam mais as seis consultas pré-natais básicas. É preciso incluir os quesitos qualidade, cidadania e huma- 
nização no cotidiano do cuidar, durante todo o ciclo grávido-puerperal, ao menos!

Ainda que quase tudo o que foi apresentado constitua em violência racial e, por conseguinte, uma forma de violência contra a mulher negra, há necessidade de se considerar ainda outros tipos quando diagnosticamos e tratamos os fenômenos de saúde apresentados pela nossa cliente afrodescendente. $\mathrm{O}$ conceito de violência contra a mulher deve basear-se na Convenção para Prevenir, Punir e Erradicar a Violência contra a Mulher (Convenção de Belém do Pará) ${ }^{(14)}$, aprovada pela Organização dos Estados Americanos OEA, em 1994, e ratificada pelo Brasil, em 1995. Neste sentido, são violência contra a mulher igualmente o assédio sexual, a violência racial, a violência contra mulheres idosas, a revista íntima, entre outras.

Uma vez que a violência contra a mulher é um problema de Estado, pois significa uma violação dos seus direitos humanos, este tem responsabilidade na adoção de ações que eliminem a violência oficial e privada, em especial para as mulheres potencialmente vulneráveis devido à sua origem étnica, idade ou outro aspecto determinado ideologicamente como inferior. Quando o Estado não toma providência quanto à violação, a Convenção outorga às pessoas e grupos o direito de recorrer à Corte Interamericana de Direitos Humanos para garantia de sua integridade.

A violência contra a mulher é também um problema de saúde. Em sua pesquisa sobre a violência doméstica contra a mulher, evidenciaram que o setor de emergência é a porta de entrada e também, na maioria das vezes, o único contato da mulher vítima de violência com o Sistema de Saúde ${ }^{(15)}$. Não havendo nem o acompanhamento posterior; nem o registro da ocorrência, o que caracteriza a discriminação nesses casos é que, dependendo da idade da vítima - uma criança, por exemplo - a atenção é outra.

Diante do que foi discutido, em que pese a universalidade ser um dos pilares do Sistema Único de Saúde, há, neste momento, que se considerar mais atentamente um outro pilar: o da equidade. A profunda diferença entre os grupos étnicos quanto aos indicadores de saúde e doença aponta que apenas as abordagens universalistas não são capazes de atingir as especificidades das mulheres negras.
Portanto, tomando por base a definição citada anteriormente sobre racismo institucional, avaliamos que a fixação do Ministério da Saúde em uma política que, ano após ano, ignora estas mórbidas diferenças entre os índices sociodemográficos e as taxas de mortalidade, constitui discriminação institucional de gênero e raça. A finalidade de tal discriminação só pode ser a manutenção de um prejuízo que conduza regular e paulatinamente à redução e ao enfraquecimento de um determinado grupo populacional (mulheres e negras[os]), visando o fortalecimento de uma estrutura de exploração do capital.

Para que se neutralize o racismo institucional e o seu impacto sobre a saúde e o bem-estar da mulher negra é necessária a promoção de um contexto político voltado para a equidade, cidadania e a emancipação que seja também culturalmente sensível, isto é, que observe as particularidades da população negra brasileira. Isto porque os conceitos de "mulher" e "negra" foram definidos socialmente e relacionados à submissão. A alteridade é uma categoria do pensamento humano, pois nenhuma coletividade se define nunca como Uma (essencial) sem colocar a Outra ("inessencial") diante de si ${ }^{(16)}$. A autora avalia que a submissão da mulher (o Outro) vem justamente dessa relação de alteridade, de reciprocidade relativa entre os grupos (para autora, homens e mulheres). Baseamo-nos no conceito de alteridade para explicar a condição de submissão da mulher para ilustrar a forma das relações verticais entre a população branca e negra no $\operatorname{Brasil}^{(16)}$.

É necessário, portanto, desconstruir esta relação de alteridade para que se promova a emancipação da pessoa e a construção de relações interpessoais baseadas na liberdade.

\section{Medidas chaves para a mudança: ações afirmativas em saúde?}

Se um resultado óbvio que um único sistema de opressão produz é extração da cidadania, mais de um sistema de opressão pode produzir a completa desumanização da pessoa. Assim, ainda que a pessoa cumpra com todos os seus deveres sociais e pague todos os seus impostos, ela não é considerada (subjetiva ou objetivamente) como uma cidadã plena com direitos ou com os mesmos direitos daquela que pertence ao grupo hegemônico. Um dos mecanismos de neutra-
A sexualidade, a saúde reprodutiva e a violência contra a mulher negra: aspectos de interesse para assistência de enfermagem 
lização ou minimização dos sistemas de opressão é a ação afirmativa que se refere a políticas e procedimentos obrigatórios e/ou voluntários estabelecidos com a finalidade de garantir a igualdade e a proteção de direitos de indivíduos historicamente discriminados, assim como combater as fontes de discriminação e retificar as práticas discriminatórias ${ }^{(17)}$.

De suma importância para a área da saúde é a ação afirmativa decorrente da aprovação da Lei 4.493/01, que exige a Notificação Compulsória da Violência Contra a Mulher atendida em serviços de urgência e emergência, assim como a criação da Comissão de Monitoramento da Violência Contra a Mulher no Ministério da Saúde e nas Secretarias Estaduais de Saúde ${ }^{(18)}$. Mas um lei pode não ser suficiente, pois, segundo a teoria racial críti$\mathrm{ca}^{(1)}$, a ação afirmativa poderá ser implementada apenas se o avanço social provocado represente também um progresso social para o grupo hegemônico. Mas caso esta ação afirmativa possa ameaçar o status quo do grupo hegemônico, ele trabalhará para que a lei se torne letra morta. Para que isto não aconteça, é necessário sensibilizar, capacitar e monitorar os profissionais e instituições de saúde quanto ao tema, admitindo que a violência contra as mulheres é um problema de saúde também, não só da polícia ou do casal.

Quanto à saúde reprodutiva, uma ação fundamental para a redução da morte materna no Brasil refere-se à necessidade premente de as escolas médicas e de enfermagem reverem seus conteúdos de obstetrícia, entre outros. É imprescindível que os procedimentos básicos sejam ensinados e os aspectos mais simples da obstetrícia possam ser diagnosticados pelo profissional generalista a ser formado. Porém, para que esta ação seja também afirmativa, torna-se necessário que a formação dos profissionais de saúde contemple o debate sobre o racismo, sua forma de atuação e as estratégias de neutralização. Igualmente é importante desenvolver nos profissionais a sensibilidade em relação à diversidade de culturas e visões de mundo.

Outra ação afirmativa importante que as(os) enfermeiras(os) devem implementar para a redução da mortalidade materna no Brasil é corrigir a falta de quadros de pessoal qualificado que possa evitar as mortes por hemorragia nas primeiras 2 horas pós-parto, decorrentes da falta de assistência nesse período. Ainda que o parto seja um fenômeno natural ele não pode ser negligenciado. Portanto, a cliente em risco para déficit do volume de líquido deve receber os mesmos cuidados que um cliente submetido a uma cirurgia quanto ao monitoramento dos sinais vitais, dos lóquios e da dor. Isto é uma responsabilidade inalienável da(o) enfermeira(o).

No nosso entendimento, nós enfermeiras(os) podemos contribuir muito para uma ação afirmativa configurada pela criação de um sistema de referência e contra-referência que vincule o pré-natal ao parto e regule a disponibilidade de leitos nas maternidades para evitar que a mulher negra cidadã, em trabalho de parto, seja obrigada a peregrinar pelas instituições mendigando uma assistência a qual tem direito ${ }^{(19)}$.

Uma relevante ação afirmativa que deve ser implementada pelas enfermeiras para a promoção da saúde reprodutiva da mulher negra, em particular, é o exercício pleno da especialidade de obstetriz. Esta ação pode garantir, no nosso entendimento, duas emancipações: a da cliente quanto ao seu corpo e ao processo do parto e a da obstetriz quanto à realização profissional e aos ganhos financeiros.

Uma outra ação afirmativa que deve ser implementada é o monitoramento da mortalidade materna e, para tal, enfermeiras e usuárias devem ter um papel relevante. Primeiramente, garantir que o item cor/raça nos documentos do SUS seja devidamente preenchido, observando o método da auto-declaração. Exigir a criação e a manutenção de Comitês Municipais e Estaduais é fundamental para o acompanhamento e o combate da mortalidade materna no Brasil, com recorte étnico. Cabe lembrar que assim como a violência contra a mulher, o óbito materno também é um evento de notificação compulsória.

Com base nos dados discutidos anteriormente, uma importante ação afirmativa para a redução da mortalidade materna é focalizar a atenção na usuária negra. Garantir o cumprimento de protocolos baseados em evidências científicas por meio de uma prática culturalmente competente deve ser o compromisso ético das(os) profissionais contra o racismo e o sexismo institucionais.

Quanto à violência real ou simbólica contra a mulher, na nossa avaliação, a prevenção 
passa pelas ações de "empoderamento" da mulher. As (os) profissionais de saúde podem (e devem) contribuir efetivamente capacitando ou instrumentalizando a mulher para que ativamente identifique e rechace qualquer conduta que atente contra seus direitos e integridade corporal. Vale destacar as interessantes experiências sobre as casas de apoio e sobre como as mulheres reconhecem o valor da casa de apoio para superação deste problema que não é pessoal, mas social ${ }^{(20-21)}$.

No nosso entender, na área da saúde as mudanças são muito lentas, mas elas ainda assim acontecem. A AACN ${ }^{(22)}$ (American Association of Colleges of Nursing), elaborou um documento no qual ressalta que, em função de sua alta incidência e prevalência, são necessárias intervenções na área da saúde e de enfermagem. Por ser uma instituição voltada para o ensino, a AACN recomenda que as Escolas de Enfermagem habilitem tanto as (os) alunas (os) de graduação quanto as (os) de pós-graduação por meio de experiências clínicas teóricas e práticas sobre a violência doméstica e racial, ao longo do ciclo vital e nos diversos cenários. Sugere ainda que as (os) pesquisadoras (os) de enfermagem devem, juntamente com pesquisadoras (os) de outros campos do conhecimento, identificar os fatores associados com o comportamento violento, assim como as ações eficazes nos níveis de atenção preventiva.

\section{Efeitos da mudança e as implicações para a(o) enfermeira(o)}

As mudanças políticas acontecem pela ação e reação dos atores sociais. Assim, cabe ressaltar que segundo a teoria racial crítica ${ }^{(1)}$, o sistema está estruturado para garantir os privilégios do grupo hegemônico e que o custo das soluções não pode ameaçar as posições conquistadas. Neste sentido, no que tange à sexualidade, à saúde reprodutiva e à violência contra a mulher, um efeito objetivo que se espera de cada profissional (mulher e homem) é que seja capaz de reconhecer sua própria atitude quanto à discriminação por raça e/ou sexo e quanto às suas manifestações de violência, incluindo a possibilidade da vitimização de si própria(o) e de pessoas de seu círculo comum e a necessidade de abordar a questão a partir de tais experiências. Afinal, as ideologias de opressão contaminam a todas(os), em maior ou menor grau.
Não é crime ter preconceito. Em alguns momentos pode ser um salutar mecanismo de defesa. Crime é ofender, discriminar ou impedir ao outro o exercício de sua cidadania, de sua condição humana, sem razões objetivas e justas para tal constrangimento ou cerceamento.

Quanto à mudança nas instituições de saúde espera-se, primeiramente, o reconhecimento da prevalência do racismo e do sexismo e das suas variadas formas de expressão. A partir deste reconhecimento, desenvolver competências para a prestação de uma assistência que seja sensível às questões de gênero e raça, identificando fatores de risco, tais como tratamento desigual, descortês ou humilhante, conversas depreciativas, atendimento com indiferença e/ou repúdio, sujeição à dor ou desconforto prolongado, entre outros, que tanto vitimizam quanto perpetuam os sistemas de opressão contra a mulher negra.

No Brasil, os cinco séculos de opressão e lutas de resistência e as pesquisas que evidenciam uma brutal diferença entre cidadãos e cidadãs deviam ajudar as(os) profissionais de saúde a diagnosticar o impacto do racismo e do sexismo sobre a saúde física e mental da clientela, ao longo do ciclo vital, e a tratar os seus efeitos, de curto e longo prazo, como também a intervir na organização das instituições de saúde e na oferta dos serviços.

$\mathrm{Da}(\mathrm{o})$ enfermeira(o) que trabalha no sentido de neutralizar o racismo e o sexismo, espera-se que implemente um histórico de enfermagem com perguntas desenvolvidas apropriadamente para a diversidade étnica e de gênero de sua clientela, comunicando-se de forma compassiva e não julgadora com a cliente. Em especial, nos casos de violência física, verbal ou psíquica, que entreviste e examine particularmente, atentando quanto ao potencial de risco para os demais membros vulneráveis do grupo familiar (crianças e idosos), e documente adequadamente no prontuário e impressos administrativos. Mantenha-se informada (o) sobre a legislação a respeito da violência e discriminação, incluindo as responsabilidades sobre a notificação compulsória, observando os princípios éticos que se aplicam a garantia do sigilo e do anonimato sobre as vítimas.

Para elaborar um plano de cuidados que resolva os diagnósticos de enfermagem cau-
A sexualidade, a saúde reprodutiva e a violência contra a mulher negra: aspectos de interesse para assistência de enfermagem 
sados pelo racismo e sexismo e vise resultados de bem-estar para a cliente, recomendamos que a(o) enfermeira(o) mantenha-se informada(o) sobre as instituições governamentais e não-governamentais que dão apoio para as vítimas de discriminação (SOS Racismo, Delegacia de Proteção à Mulher, entre outros, por exemplo) de modo a poder encaminhar a(o) cliente vítima. O plano deve contemplar principalmente os cuidados dirigidos ao enfrentamento da discriminação.

No plano comunitário e político, recomendamos o desenvolvimento de um plano assistencial que incremente a consciência pública sobre os sistemas de opressão (racismo e sexismo), por meio de campanhas informativas, por exemplo. A implementação de atividades para promoção saúde e para o desenvolvimento de estratégias de enfrentamento do racismo e do sexismo, assim como de empoderamento, na população de mulheres negras, ao longo do ciclo vital, que propiciem mudanças comportamentais relativas à baixa auto-estima crônica e/ou à síndrome de espancamento.

\section{CONSIDERAÇÕES FINAIS}

Em síntese, podemos concluir, com base na literatura analisada e no referencial da teoria racial crítica, que o discurso da mulher negra ainda não é considerado uma evidência empírica para a maior parte das pesquisas. Mas, ainda assim, foi possível depreender que há uma demanda da mulher negra quanto às instituições e aos profissionais de saúde no que se refere à sua sexualidade, sua saúde reprodutiva e às situações de violência dirige-se a todos os níveis de atenção à saúde, assim como à estrutura de poder. Essa demanda supera os aspectos estritamente biológicos porque as mulheres e os homens solidários, das diversas etnias, credos e profissões, usuárias(os) e profissionais, se mobilizaram socialmente pela explicitação da discriminação institucional e também pela mudança.

Os problemas de saúde/doença, bem-estar/mal-estar vivenciados pelas mulheres negras não podem ser mais considerados como conseqüência da falta de desenvolvimento econômico apenas e precisam ser compreendidos como problemas de saúde que realmente são. Neste sentido, buscamos relacionar neste estudo, com base na literatura profissional e feminista, algumas intervenções de saúde, a título de ações afirmativas, passíveis de serem implementadas pela própria cliente (autocuidado) e pelas (os) enfermeiras(os), pela sociedade civil organizada e pelas (os) gestores do SUS.

Com base no que foi discutido, reiteramos a necessidade de se realizarem mais pesquisas sobre mulheres negras e sobre os mecanismos de geração e prevalência da violência, a partir de um referencial humanista e emancipador, tal como o da teoria racial crítica. Igualmente urge a proposição de políticas públicas de saúde e educação que garantam os direitos humanos de um segmento significativo e vulnerável da população: a mulher negra, de modo a propiciar a correção, em curto e médio prazos, das distorções apontadas.

\section{REFERÊNCIAS}

(1) Agulefo, U, Thornton C, Bakenhus I, Benn S, Holmes C. Critical race theory. [online] Austin: University of Texas; 2001. Available from: http://www.edb.utexas.edu/faculty/ scheurich/proj7/criticalrace.htm (07 ago. 2003).

(2) Castro R, Riquer F. La investigación sobre violência contra las mujeres em América Latina: entre el empirismo cego y la teoria sin datos. Cad Saúde Pública 2003; 19(1):135-46.

(3) The Lancet Institutionalised racism in health care. The Lancet 1999; 353 (9155):765.
(4) Cruz ICF. Health and African-Brazilian Ethnicity Research Group. Online Brazilian J Nurs 2002; 1 (1). Available from: www.uff.br/ nepae/africanbrazilianhealth.htm (06 ago. 2003)

(5) Bandeira L, Batista AS. Preconceito e discriminação como expressões de violência. Rev Estud Fem 2002; (10)1:119-41.

(6) Cruz ICF, Hoga LAK. Alguns aspectos sobre saúde/doença em mulheres negras. Rev Baiana Enferm 1998; 11(2):50-60. 
(7) Batista LE. Mulheres e homens negros: saúde, doença e morte [tese]. Araraquara(SP): Universidade Estadual Paulista; 2002.

(8) Cruz ICF, Pinto A. Condições para a saúde e o bem-estar? Inquérito sobre as mulheres negras do Estado do Rio de Janeiro. Cad Saúde Pública 2002; 18(1):340-1.

(9) Johnson M, Maas M, Moorhead S, editors. Nursing Diagnosis, Outcomes \& Interventions. NANDA, NOC, and NIC Linkages. Saint Louis: Mosby; 2001.

(10) Cruz ICF. Sensualidade, sexualidade e emancipação: subsídios para a discussão sobre a subjetividade da mulher negra. Rev Enferm UERJ 1995; 3(2):227-32.

(11) Cardoso CP, Porto JRR, Homero MNT, Hecker AM. Violência contra a mulher e a feminização da incidência de HIV/AIDS. Bol Maria Mulher [periódico online] 2002; 2(2):3.

(12) Petry S. Até na hora do parto negra é discriminada. Folha de São Paulo [periódico online] São Paulo; 2002 mai. 25. Disponível em: http://www1.folha.uol.com.br/folha/cotidiano (25 mai. 2002)

(13) Organização Pan Americana de Saúde (OPAS). Política nacional de saúde da população negra: uma questão de eqüidade. Brasília: PND/ OPAS; 2002.

(14) Barsted L. Violência contra a mulher: conceito. [online] Rio de Janeiro: Biblioteca Virtual da Mulher/CEDIM; 2004. Disponível em: http://www.prossiga.br/bvmulher/cedim (26 jun. 2003)

(15) Deslandes S, Gomes R, Silva CMFP. Caracterização dos casos de violência doméstica contra a mulher atendidos em dois hospitais públicos do Rio de Janeiro. Cad Saúde Pública $2000 ; 16(1): 129-37$.
(16) Beauvoir S. O segundo sexo, 1: fatos e mitos. São Paulo: Difel; 1960. p.10-2.

(17) Heringer R. Ação afirmativa e combate às desigualdades raciais no Brasil: o desafio da prática. Bol Inf PPCor/Laboratório de Políticas da Cor UERJ [periódico online] 2003; 7. Disponível em: http://www.lpp-uerj. net/olped/documentos/ppcor/ppcor152.pdf (01 dez. 2003)

(18) Casa de Cultura da Mulher Negra. Notificação compulsória sobre a violência contra a mulher. Bol Eletron Eparrei 2002, SP, Casa de Cultura da Mulher Negra. [mensagem pessoal]. E-mail para Isabel C. F. da Cruz <isabelcruz@uol.com.br>(20 set. 2002)

(19) Rede Feminista de Saúde. Dossiê de mortalidade materna [online] Disponível em: $<$ http:/ /www.redesaude.org.br/dossies/html/ dossiemortmaterna.html (23 ago. 2003)

(20) Meneghel SN, Camargo M, Fasolo LR, Mattiello DA, da Silva RC, Santos TC et al. Mulheres cuidando de mulheres: um estudo sobre a casa de apoio Viva Maria, Porto Alegre, Rio Grande do Sul, Brasil. Cad Saúde Pública 2000; 16(3):747-57.

(21) Alves AM, Coura-Filho P. Avaliação das ações de atenção às mulheres sob violência no espaço familiar, atendidas no Centro de Apoio à Mulher (Belo Horizonte) entre 1996 e 1998. Ci Saúde Coletiva 2001; 6(1):243-57.

(22) American Association of Colleges of Nursing $(\mathrm{AACN})$. Violence as a public health problem [online] Whashington (DC): AACN; c2002. Available from: http:/www.aacn.nche.edu/ Publications/positions/violence.htm (24 ago. 2003)
A sexualidade, a saúde reprodutiva e a violência contra a mulher negra: aspectos de interesse para assistência de enfermagem 